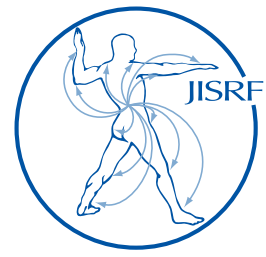

\title{
Experience with Modular Necks for Cemented Total Hip Arthroplasty
}

\author{
Cameron $\mathrm{H}^{1}$, McTighe $\mathrm{T}^{2}$
}

\begin{abstract}
This is a retrospective review of the senior surgeons series ( Model I and II) of using the same-cemented stem and modular neck design $\left(\mathrm{R}-120^{\mathrm{TM}}\right)$ with the exception that the second series had an improved modular neck construct. Model I, 145 stems implanted between 2002 and 2005. Taper neck problems consisted of two neck trunnion fractures at the neck-stem junction and one modular neck disassociation at the modular junction. The stem was voluntary withdrawn from the market and redesigned to a more robust structure.

Model II, 188 cemented-stems were implanted between 2007 and 2011 by the senior author utilizing the same surgical technique. There have been no modular neck taper problems in this series. This paper will demonstrate that once a modular junction problem has been identified corrective action can be taken to resolve the problem. We believe that there is a benefit to a modular neck-stem junction cemented stem design, and that all modular junctions are not equal in design or function.
\end{abstract}

Keywords: cemented stem, modular neck, trunnion, taper junction

Level of Evidence: AAOS Therapeutic Level III

\section{Introduction}

Cemented stems are still widely used in total hip arthroplasty (THA) especially in Europe, [1,2] however there are still concerns with adverse effects of bone cement in that biomaterial properties of the cement contribute to the pathologic state that separates this disease from other modes of mechanical loosening. This leads inevitably to the conclusion that Cement Disease does exist [3]. The senior author still uses cement in 15 to 20 percent of cases in Dorr type $\mathrm{C}$ bone.

1 Hugh U. Cameron, MB, ChB, FRCSC

Sunnybrook, Health Science Centre, Holland Orthopaedic \& Arthritic Centre, 43 Wellesley St. East, Toronto, ON Canada M4Y 1H1

2 Timothy McTighe, Dr. HS (hc), Joint Implant Surgery \& Research Foundation, 46 Chagrin Shopping Plaza, \#117, Chagrin Falls, OH 44022 US

(Direct reprint requests to Timothy McTighe)
Dislocations continue to be a significant problem in THA regardless of stem fixation method (cement or cementless) and in theory modular necks provide features to adjust both femoral offset and version orientation. The causes of dislocations, can be multi-factorial, and include: soft tissue laxity, malpositioned components resulting in mechanical impingement of component on component or component on fixed obstructions such as osteophytes. Encountering these factors, stability is often achieved at the expense of limb lengthening. [2,4,5]

Leg-length discrepancy after THA can present consid-

\footnotetext{
(C) 2016 Cameron, McTighe. All rights reserved.

Authors retain copyright and grant the journal right of first publication with the work. Reconstructive Review follows the Creative Commons Attribution-NonCommercial CC BY-NC. This license allows anyone to download works, build upon the material, and share them with others for non-commercial purposes as long as they credit the senior author, Reconstructive Review, and the Joint Implant Surgery \& Research Foundation (JISRF). An example credit would be: "Courtesy of (senior author's name), Reconstructive Review, JISRF, Chagrin Falls, Ohio".
} 
erable difficulty for the patient, such as nerve palsy, low back pain, abnormal gait and dislocation with leg shortening. Patient dissatisfaction with leg-length discrepancy after THA is the most common reason for litigation against orthopaedic surgeons. [6]

Reconstruction of the joint mechanics (combined anteversion) to prevent impingement of the stem on the cup and avoidance of bone-on-bone requires correct restoration of hip neck length and femoral offset regardless of cement or cementless fixation $[7,11]$. The senior author's cement technique uses a broad stem design with a smaller cement mantel as compared to other European style stems (Execter) so intraoperative version adjustment is limited.

Traditional cemented and cementless stems since the 1980s have had one common denominator that being a modular head neck taper junction. The success of a selflocking taper is influenced by the design of the taper, particularly the taper angle, the roughness, and the mating materials between the "male" and "female" components. The major advantage of modularity at this junction was to provide some level of adjustment of leg length or vertical height to reduce leg length discrepancy. Version and femoral offset were still difficult to adjust or fine-tune and as a result of growing acceptance of modularity the neck-stem junction seemed to be the next logical area of product development. [8].

Individual modular design parameters can offer significant advantages for both fit and fill of implant to bony structures while providing more options for intraoperative customization of joint mechanics and provide significant economic value in reducing levels of finished goods inventory. Now, amid reports of clinical incidents in which metal modular junctions have demonstrated fretting, corrosion, and pseudotumors, there is renewed interest as to what causes these junctions to fail. The recent fall in the use of modularity can be contributed primarily to concerns with inflammatory reactions to metal debris. Can failures be predicted or avoided? When a failure does occur what can be done about it? [9]

This paper will highlight one specific modular neck-stem junction that encountered mechanical failure with a first generation product. With observation and analysis of these failures, the manufacturer identified the problem and reintroduced an improved secondgeneration design. Since this secondgeneration prosthesis was introduced, there have been no failures in our cohort of patients since 2007. A 9-year follow up. (Figure 1)

\section{Material and Methods}

\section{MODEL I}

Original cemented stem R-120 $0^{\mathrm{TM}}$ by Osteoimplant Technology Inc. (OTI) Hunt Valley, Maryland, USA. Stem and modular necks are manufactured from $\mathrm{CoCr}$ alloy. The shape of the stem is trapezoidal with a large collar that provides for impaction and compression of the cement. The stem collar is made with a cavity where a self-locking taper and a positive indexing mechanism provide 12 different positions to ensure proper restoration of joint mechanics (Figure 2).

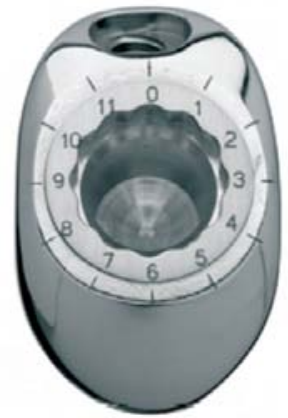

Figure 2. Patented 12 indexable modular neckstem junction allows for fine-tuning joint mechanics.

145 stems were implanted between 2002 and 2005 in 50 males and 95 females. Mean age 72 with 2 patients under the age of $60 . \mathrm{CoCr}$ heads 28 or $32 \mathrm{~mm}$ were used and all cups were cemented polyethylene sockets. Surgical incision for both cohort of patients (Model I \& Model II) was a Modified Anterolateral Watson-Jones Approach.

Neck Positions: (Figure 3, Tables 1,2,3)

Table 1.

\begin{tabular}{|c|c|c|}
\hline Positions Varus/Valgus & Number of Cases & Percentage of Cases \\
\hline $8^{\circ}$ & 82 & $56 \%$ \\
\hline $12^{\circ}$ & 63 & $44 \%$ \\
\hline
\end{tabular}

Table 2.

\begin{tabular}{|c|c|}
\hline Neck Length in mm & Number of Patients \\
\hline 32 & 74 \\
\hline 35 & 68 \\
\hline 38 & 3 \\
\hline
\end{tabular}

Table 3.

\begin{tabular}{|l|c|c|}
\hline Positions & $\begin{array}{c}\text { Number of } \\
\text { Cases }\end{array}$ & $\begin{array}{c}\text { Percentage } \\
\text { of Cases }\end{array}$ \\
\hline Anteverted & 2 & $2 \%$ \\
\hline Neutral & 57 & $39 \%$ \\
\hline Retroverted & 86 & $59 \%$ \\
\hline
\end{tabular}

Figure 3. Modular Neck $(\mathrm{CoCr})$, available in both $8^{\circ}$ \& $12^{\circ}$ versions, 3 neck lengths $32 \mathrm{~mm}$, $35 \mathrm{~mm}, \& 38 \mathrm{~mm}$

- If the neck was not modular $61 \%$ would not have been in the optimal position resulting in increased risk for mechanical impingement as determined by intraoperative trial range of motion. 


\section{MODEL II}

Maintained the same stem shape and dimensions with the exception of the modular neck stem junction. The failure mode of the model I design was basic fatigue failure caused by an under-designed modular junction.

188 stems implanted between 2007 and 2011 in 79 males and 109 females. Mean age 75 with 14 being younger than 65 years of age. All stem were cemented and all cups were non-cemented with porous press fit hemispherical components.

\section{Neck Positions:}

Table 2.

\begin{tabular}{|c|c|}
\hline Neck Length in mm & Number of Patients \\
\hline 32 & 104 \\
\hline 35 & 37 \\
\hline 38 & 2 \\
\hline
\end{tabular}

Table 3

\begin{tabular}{|l|c|c|}
\hline Positions & Number of Cases & $\begin{array}{c}\text { Percentage of } \\
\text { Cases }\end{array}$ \\
\hline Anteverted & 3 & $2 \%$ \\
\hline Neutral & 48 & $26 \%$ \\
\hline Retroverted & 137 & $73 \%$ \\
\hline
\end{tabular}

- All femoral heads for both series were $28 \mathrm{~mm}$ or $32 \mathrm{~mm}$ diameter. $32 \mathrm{~mm}$ diameter is preferred head size with improved highly crosslinked polyethylene.

\section{Fatigue Failure}

Repeated cycling of the load causes metal fatigue. It is a progressive localized damage due to fluctuating stresses and strains on the material. Metal fatigue cracks initiate and propagate in regions where the strain is most severe. The process of fatigue failure consists of three stages $[9,10]$ :

- Initial crack initiation

- Progressive crack growth across the part

- Final sudden fracture of the remaining cross section of the material
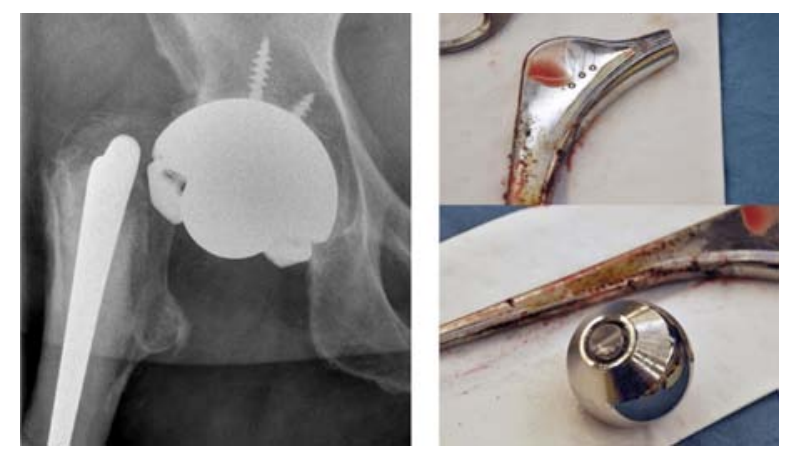

Figure 4. Fractured Monoblock Femoral Neck in a Cemented Execter Stem. (Source Unknown)
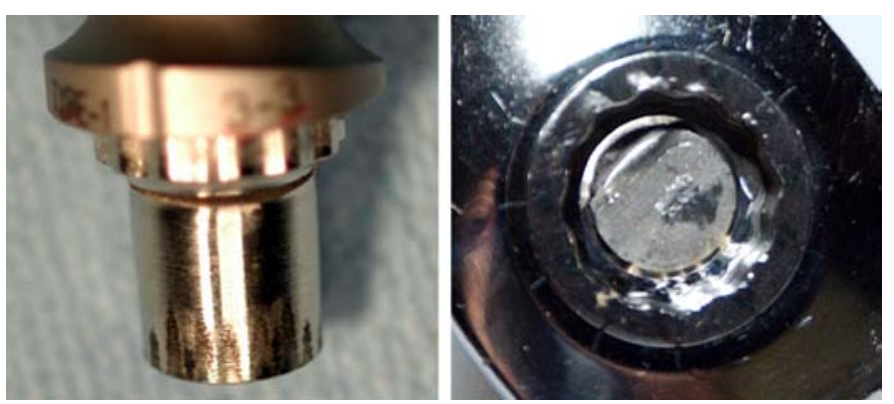

Figure 5. Pictures showing a fatigue failure of Model I in explanted OTI Co-Cr modular neck and close up of broken neck within the stem cone body. Stem, neck and head are Co-Cr. (Courtesy JISRF archives)

All devices are subject to fatigue failure especially with the increased patient activity we are seeing today. There are reports of device failure regardless of material, and regardless of design style (monoblock, modular) (Figures 4, 5) [10].

\section{Design Improvements}

Improvements made to this novel neck design, which increased surface contact by $40 \%$, included specific size increases of the taper trunnion that improved mechanical strength from 520-700 lbs. to greater than 1,200 lbs. [9,10] (Figure 6)
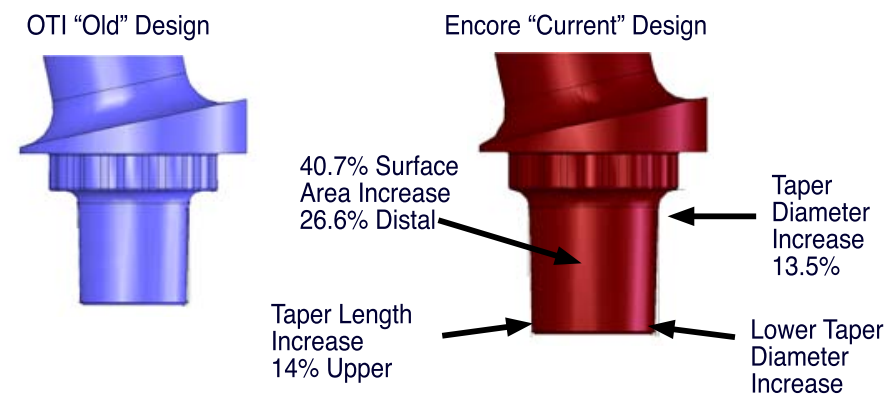

Figure 6. Illustration showing modular taper improvements from the original OTI ${ }^{T M}$ design to the Encore improvement design. (Courtesy JISRF Archives)

\section{Results}

\section{MODEL I}

In our cohort of 145 patients with Model I of the R-120 modular neck cemented stem all femoral components, modular head, modular neck and stem were Co-Cr material. Five patients presented with sudden symptoms of generalized hip, groin and buttock pain and inability to ambulate. Evaluation demonstrated 3 patients with modular neck stem junction failures. 2 modular neck fatigue fractures as depicted in figure 5 and figure 7. One fractured neck was revised to a long cementless S-Rom ${ }^{\circledR}$ stem (Figures $7 \mathrm{a}, 7 \mathrm{~b}$ ). 


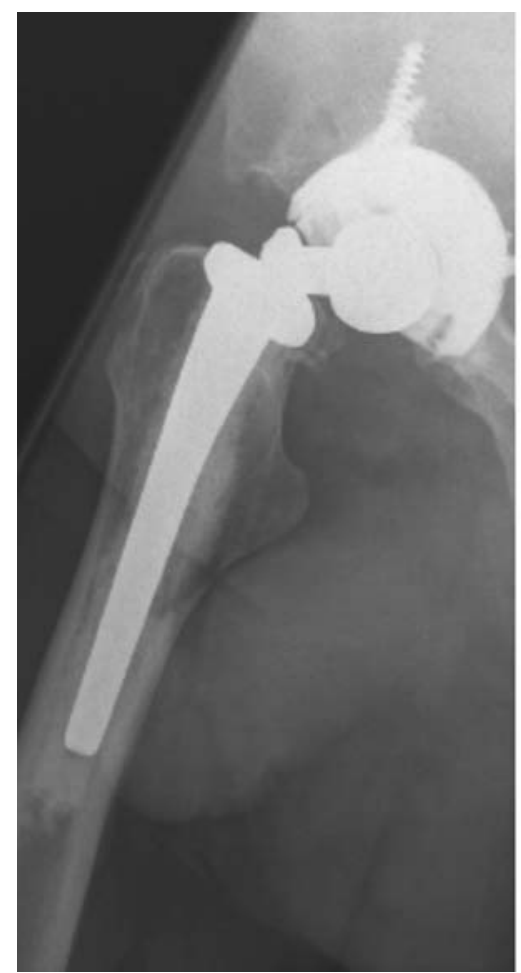

Figure 7a. Fatigue failure of Model I $R$-120 modular neck cemented stem. (Courtesy Cameron)

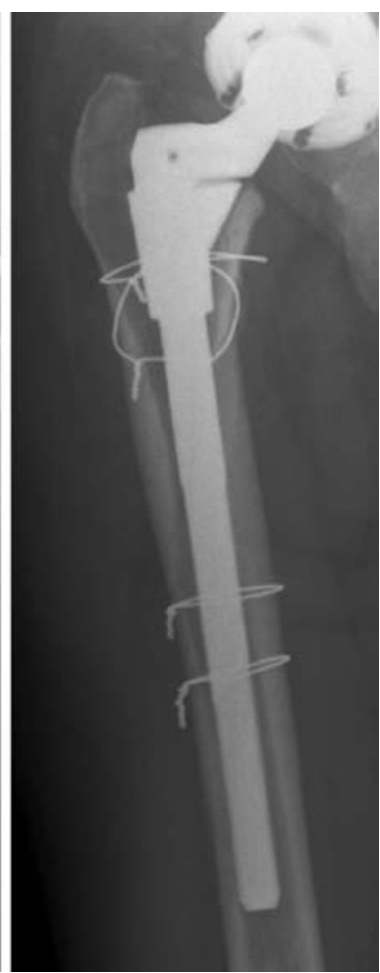

Figure 7b. Revised Model I R-120 modular neck cemented stem with a long cementless $S$-Rom $\circledR$ stem. (Courtesy Cameron)

Second fractured neck was revised with tap-out, tap-in technique as the Model II stem was identical in size and shape but had the improved modular neck-stem junction (Figures 8a, 8b).
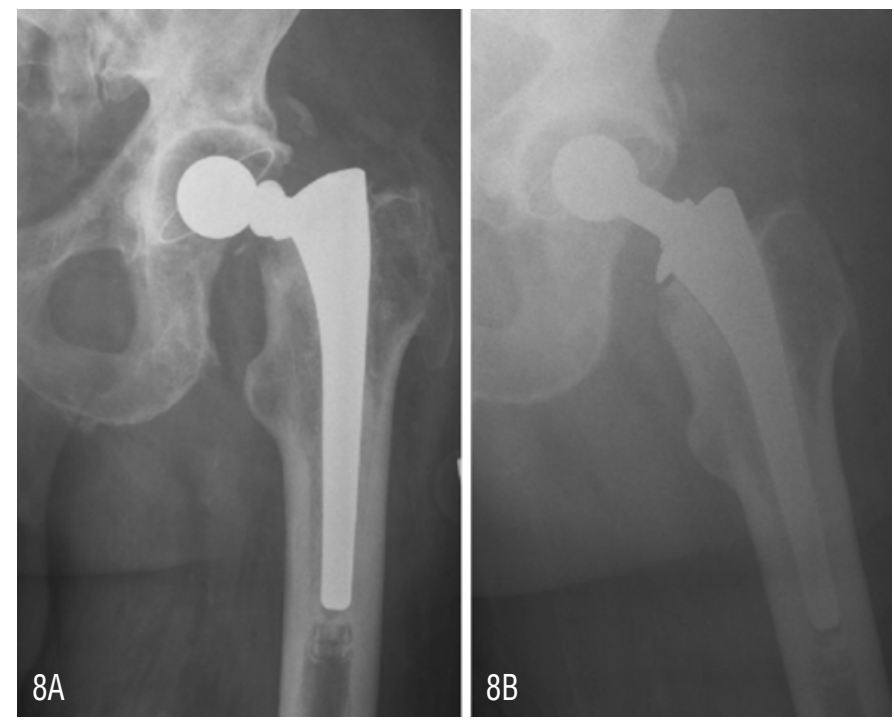

Figure $8 A$ \& B. Fatigue failure on Model I R-120 modular neck revised to a improved Model II $R$-120 modular neck. Implanted with tap out tap in technique. (Courtesy Cameron)

- Both modular neck fatigue failures had $35 \mathrm{~mm}$ neck lengths with a long modular Co-Cr femoral head.

- 1 modular neck disassociation was revised to a cementless S-Rom stem.

- 1 stem removed during cup revision (stem was well fixed however senior author wanted more intraoperative options so stem was replaced with a S-Rom stem.)

- 1 late sepsis

- 2 bisphosphonate fractures (both were revised to a SRom stem)

Three modular neck-stem failures resulting in explantation represents a $2 \%$ revision rate. A total of 7 revisions out of our cohort of 145 represents an overall revision rate of $4 \%$.

\section{MODEL II}

In our cohort of 188 implanted stems with the Model II R-120 modular neck cemented stem there were no issues with the modular junction.

- Intraoperative complications, 6 calcar fractures all cerclaged

- 1 case of late infection (7 years)

- 1 dislocation at two years (closed reduction)

- 0 modular neck problems

\section{Discussion}

The initial series of Model I had a modular neck complication in three cases out of 145 implanted stems, for a $2 \%$ complication rate of the modular neck-stem junction. The manufacture (OTI / Encore) based on additional reports voluntarily withdrew Model I from the market (2006). After additional testing and development an improved modular junction (Model II) was reintroduced (2007) with the same overall design features of the original R-120 cemented stem.

In our Model II series there has been no complications with the modular neck-stem junction out of 188 stems implanted.

Combined results on 333 stems implanted for modular neck-stem junction problems were three or a $1 \%$ complication rate. Further in this combined series of using this novel modular junction design fabricated with the same material as the stem $(\mathrm{CoCr})$ there have been no cases of delayed hypersensitivity and no cases of pseudo tumors.

The novel finding of indexing the neck orientation into a position of retroversion was 223 stems out of a combined total of 333 or $66.9 \%$. This figure is similar to results of the usage of angled modular necks used with the ARC ${ }^{\text {TM }}$ cementless neck-sparing stem in a review series of 1,790 stems implanted with $64 \%$ being positioned other than 
neutral. [12]

Combined anteversion (CA) is the sum of cup anteversion and stem antetorsion (AT) that provides a parameter to asses the overall cup and stem alignment. However, there are a variety of studies published that recommend different implant orientation positions. [13] Lewinnek recommends $40^{\circ} \pm 10^{\circ}$ of inclination and $15^{\circ} \pm 10^{\circ}$ of Anteversion (AV). Biederman reported that $\mathrm{AV}$ of $15^{\circ}$ and inclinations of $45^{\circ}$ were associated with the lowest risk for dislocation. Wixson proposed cup positioning with inclination of $40-45^{\circ}$ and $\mathrm{AV}$ of $17-23^{\circ}$ with the posterior approach. [13]

So is there a definitive set of numbers for $\mathrm{CV}$ to reduce mechanical impingement and dislocation? Obtaining optimal implant positioning is critical for reducing these complications. Our experience with modular necks demonstrate that the best mechanism available is trial range of motion with trial implants. Modularity at the neck-stem junction provides for fine-tuning implant orientation prior to final implantation of definitive components. Often the final orientation of the femoral neck as determined by trial range of motion indicates a head-neck position of retroversion.

Modular neck design aids in fine-tuning joint mechanics after stem insertion, and allows for ease and access in case of revisions (Figure 9). [14]
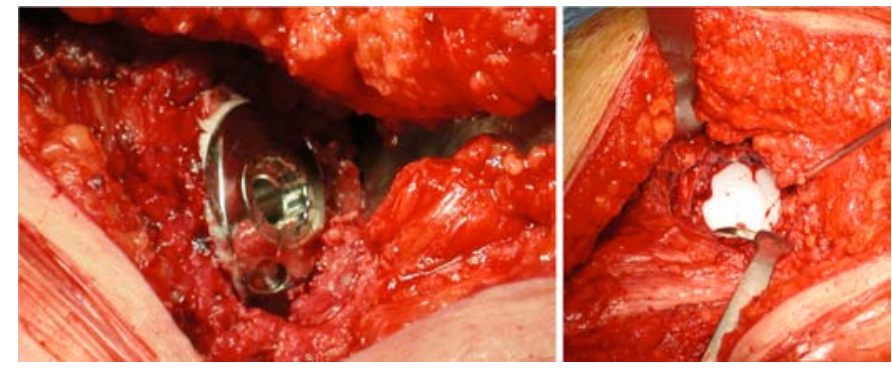

Figure 9. Stem cemented in place without neck showing access to socket. (Courtesy Cameron)

In our combined series of 333 stems implanted we had one postoperative dislocation for a dislocation rate of $0.3 \%$. Two fatigue failures and one modular junction disassociation in Model I cohort of 145 stems implanted represent a failure rate of the modular junction of $2 \%$. Combined series total of 333 stems implanted had a $0.9 \%$ complication rate of the modular neck-stem junction.

Manufacturers have all but discontinued modular neckstem designs because of first generation failures. This, in our opinion, is a mistake. Fatigue failures of this first generation design have been identified and the redesigned modular junction (Model II) with 188 stems implanted between 2007 and 2011 have not demonstrated any modular junction complications. To give up on design concepts that have viable contributions to improve clinical outcomes is a failure in itself.

Our early pioneer surgeons (Sir John Charnley, Maurice Muller, Charles O. Bechtol, Charles Townley and others) did not surrender to early failures. They reviewed, learned and improved clinical surgical results for Total Hip Arthroplasty.

Product and surgical techniques need to be tightly controlled during the early stage of development and fully evaluated before general market release.

This improved model II R-120 cemented modular neckstem junction has proven to be safe and efficient in our series and we encourage the manufacture not to give up on it (Figure 10).

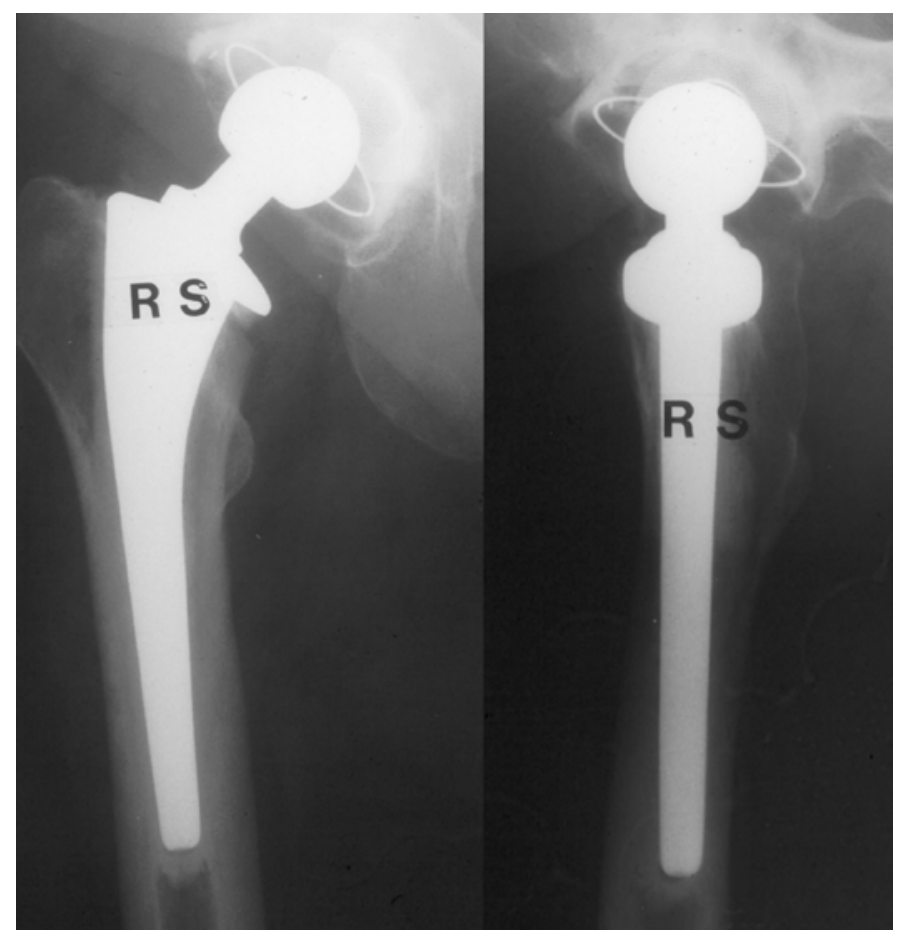

Figure 10. Post-op of $R-120 \mathrm{~A} / \mathrm{P}$ X-rays cemented in place, neck in position one slightly retroverted.(Courtesy Cameron)

\section{Conclusion}

Modular neck-stem junctions have been under criticism as a result of fatigue failure and trunnion corrosion. Our experience with this novel modular junction has the benefit of being fabricated using the same material $(\mathrm{Co}-\mathrm{Cr})$ for the stem, neck and femoral head. Failures in the first generation demonstrated that the modular junction was under designed with regard to overall fatigue strength. This has been correct by increasing male taper diameter by $13.5 \%$, taper length increase by $14 \%$ resulting in a $40.7 \%$ increase in surface area.

Further in this combined series of using this novel mod- 
ular junction design fabricated with the same material as the stem $(\mathrm{Co} \mathrm{Cr})$ there have been no cases of delayed hypersensitivity and no cases of pseudo tumors.

The senior surgeon still uses this modular neck-stem cemented stem and will continue to follow these cases.

\section{Disclosure Statement}

The authors declare that there is no conflict of interest regarding the publication of this paper. For full disclosures refer to last page of this journal.

\section{References}

1. Guerin S, and Jones C. Cemented Femur. In: Cashman J, Goyal N, Parvizi J, eds. The Hip: Preservation, Replacement and Revision. Baltimore, MD: Data Trace Publishing Company; 2015: 71-1 to 71-10.

2. Cameron H,Leslie, C, McTighe T. Design Considerations and Results for a Modular Neck in Cemented THA. Conference: The 21st Annual Conference of the International Society for Technology in Arthroplasty, At Seoul, Korea. Poster Exhibit DOI: http://dx.doi.org/10.13140/RG.2.1.1893.6082

3. Jones LC, Hungerford DS. Clin Orthop Relat Res. Cement disease. 1987 Dec;(225): 192

4. McTighe T, Keggi K, Reynolds HM, Smit M, Keggi J, Cameron HU, Stulberg B. Design Considerations for a Modular Neck in Total Hip Arthroplasty. Conference: OARSI Annual Meeting 2003, Volume: Poster Exhibit DOI: http://dx.doi. org/10.13140/ RG.2.1.1346.1606

5. Benedetti MG, Catani F, Benedetti E, Berti L, Di Gioia A, and Giannini S. To what extent does leg length discrepancy impair motor activity in patients after total hip arthroplasty? International Orthopaedics (SICOT) (2010) 34:1115 -1121 / DOI http://dx.doi.org/10.1007/s00264-009-0855-5
6. Clark CR, Huddleston HD, Schoch EP, and Thomas BJ. Leg-Length Discrepancy After Total Hip Arthroplasty. J Am Acad Orthop Surg 2006; 14: 38-45

7. Clark CR, Huddleston HD, Schoch EP, and Thomas BJ. Leg-Length Discrepancy After Total Hip Arthroplasty. J Am Acad Orthop Surg 2006; 14: 38-45

8. McTighe T, Trick L, and Koeneman JB. Design Considerations for Cementless Total Hip Arthroplasty. In book: ENCYCLOPEDIC HANDBOOK OF BIOMATERIALS AND BIOENGINEERING, Edition: Part B: Applications Volume I 1995, Publisher: Marcel Dekker, Inc., pp. 3 to 43. DOI: http://dx.doi.org/10.13140/ RG.2.1.2919.0240

9. McTighe T, Brazil D, Clarke I, Keppler L, Keggi J, Tkach T, and McPherson E. Metallic Modular Taper Junctions in Total Hip Arthroplasty. JISRF • Reconstructive Review • Vol. 5, No. 2, July 2015. DOI: http://dx.doi.org/10.15438/rr.5.2.108

10. Keggi K, Keggi J, Kennon R, Tkach T, et. al. Within Any Important Issue, There are Always Aspects No One Wishes to Discuss" - Femoral Component Failure. Conference Poster, ISTA, September 2006. DOI: http://dx.doi.org/10.13140/ RG.2.1.4779.6329

11. Lawrence D. Dorr, Aarner Malik, Manish Dastane and Zhinian Wan, Combined Anteversion Technique for Total Hip Arthroplasty. Clin Orthop Relat Res. 2009 Jan; 467(1): 119-127. Published online 2008 Nov 1.doi: http://dx.doi. org/10.1007/s11999-008-0598-4

12. Timothy McTighe, John Keggi, Louis Keppler et al. The First 1,200 (1,790) U.S. Short Curved Neck Stabilized Stems. ISTA Annual Conference, October 2012, Sydney, Australia. DOI: http://dx.doi.org/10.13140/RG.2.1.4431.0168

13. Shigeo Fukunishi, Tomokazu Fukui, Shoji Nishio et. al. Combined Anteversion of the Total Hip Arthroplasty Implanted with Image-Free Cup Navigation and without Stem Navigation. Orthopedic Reviews 2012; volume 4:e33 doi: http:// dx.doi.org/10.4081/or.2012.e33

14. McTighe T, and Tkach T. Design Considerations for Modular Junctions. Conference: Research on Modularity Hip Scientific Meeting sponsored by Global Orthopaedic Technology Oct. 9-10, 2009, At Gold Coast, Australia, Volume: Oral Paper DOI: http://dx.doi.org/10.13140/RG.2.1.2957.5441 